\title{
The Imaging of Legg-Calve-Perthes Disease
}

\author{
Dmitry A. Lezhnev, MD, ScD; Nataliya A. Sholohova, MD, PhD; \\ Alla M. Ganieva, MD; Alexander Yu. Vasilyev, MD, ScD*; Elena A. Egorova, MD, ScD; \\ Elena B. Olkhova, MD, ScD; Viktor P. Truten, MD, ScD; Margarita V. Smyslenova, MD, ScD; \\ Viktoriya V. Petrovskaya, MD, ScD; Margarita O. Dutova, MD \\ Moscow State University of Medicine and Dentistry named after A. I. Evdokimov \\ Moscow, the Russian Federation
}

\begin{abstract}
Diagnosis of hip joint pathology remains a serious problem in childhood and adolescence. A wide range of pathologiesincluding dysplastic, dystrophic, inflammatory, oncological and post-traumatic diseases of the musculoskeletal system-leads to the advancement of imaging methods and techniques. Legg-Calve-Perthes disease (LCPD) is a common cause of hip pain in children that may be initially clinically and radiographically difficult to diagnose Radiography of the pelvis in two views (anteroposterior and Lauenstein) is the main method of diagnosing aseptic necrosis. Destructive changes of the femoral head and neck of the femur are clearly determined. However, the presence of X-ray negative patterns at the first stage of the disease and the impossibility of visualizing all the anatomical structures induce us to improve the diagnostic algorithm of this difficult pathological process. (International Journal of Biomedicine. 2019;9(1):9-12.)
\end{abstract}

Key Words: Legg-Calve-Perthes disease $\bullet$ osteochondropathy $\bullet$ hip pain $\bullet$ radiography $\bullet$ MRI

$\mathrm{M}$ usculoskeletal diseases are a prevalent modern health problem that leads to social maladjustment. Among the widespread disabling orthopedic diseases, there is a group of nosologies accompanied by aseptic osteonecrosis. The imaging of the femoral head is the most important topic due to its significant influence on the quality of life. According to the severity of the impairment, one out of every 11 patients with a hip disorder eventually is disabled, whereas in cases of other diseases of the musculoskeletal system, only one out of every 100 patients becomes handicapped. ${ }^{(1)}$

LCPD is an osteochondropathy, with the lesions of the proximal femur and hip joint caused by disruption of the blood supply to the cartilage, resulting in necrosis of the femoral head. ${ }^{(2)}$ According to Russian state statistics, the incidence of LCPD among the hip joint diseases within the pediatric population is $15 \% \cdot{ }^{(3)}$ The disease has been known for over 100 years; however, studies concerning its causes, development,

"Corresponding author: Prof. Alexander Yu. Vasilyev, MD, $P h D, S c D$. Department of Radiology, Moscow State University of Medicine and Dentistry named after A. I. Evdokimov, Moscow, Russia.E-mail:auv62@mail.ru diagnosis and treatment are still in progress. In the early 20th century, this disease was mentioned in reviews as casuistic observations; in the 1990s, its frequency increased 10 times. The proportion of aseptic necrosis of the femoral head is about $15 \%$ among other orthopedic diseases. ${ }^{(4)}$

The etiology of the disease has not been finally established. Because neither of the theories could answer the questions about its origin, LCPD should be considered as a multifactorial disorder with congenital and acquired causes. ${ }^{(5,6)}$

The diagnosis of hip joint dysplasia and LCPD in children remains an urgent problem due to social consequences of unsatisfactory results of treatment. It should be mentioned that the patient's quality of life depends on when the disorder is detected. ${ }^{(3)}$

The data of imaging modalities for hip pathology have increased in recent years. The well-known methods have been essentially improved and become more informative; the minimally invasive techniques have also been upgraded. Despite all existing methods of diagnosis, the early detection of aseptic femoral head necrosis in the Russian Federation is estimated to be about $15 \%$. $^{(7)}$ It is difficult to determine the risk groups for this disease; there are no pathognomonic 
clinical signs, so the patients often seek medical attention at the clinical stage with considerable bone destruction. ${ }^{(8)}$

The onset of the disease usually occurs at the age of 4 to 12 , with the highest incidence in 4- to 8-year-old children, though it may happen in adolescence. Boys suffer 3-5 times more often than girls. The frequency of bilateral LCPD amounts $10 \%$, the disease lasts from 2 to $6-8$ years, and it is difficult to date the onset of the disease. The first clinical manifestations are pain in the hip joint radiating to the femur and the knee, limping, and early fatigue during physical exercises. The pain appears in the moment of movement and disappears at rest. LCPD is a common cause of hip pain in children that may be initially clinically and radiographically difficult to diagnose. ${ }^{(9)}$

The clinical examination demonstrates the painful restriction of hip joint movement in abduction and rotation. There is a hypotrophy of gluteus and femoral muscles, a positive Trendelenburg's symptom, and feet of different lengths although the general condition of children does not suffer. The results of general analyses are normal, but they should be done to exclude other pathology. ${ }^{(5,6)}$

In the International Statistical Classification of Diseases and Related Health Problems (ICD 10), LCPD is referred to the group of chondropathies and called «Juvenile osteochondrosis of head of femur».

There are several classifications of LCPD; the most popular are those of RP Ficat \& J. Arlet (1980), Steinberg (1995), and DC Mitchell (1987). The classification by RP Ficat \& J. Arlet ${ }^{(10)}$ is more useful and widespread: it includes the clinical data, and radiographic and MRI findings, for the aseptic necrosis staging:

\section{$\underline{\text { Stage } 0}$}

Radiography: no pathology

MRI: no pathology

Clinical picture: absent

\section{$\underline{\text { Stage I }}$}

Radiography: no pathology or minimal osteopenia

MRI: edema

Clinical findings: pain irradiating to the inguinal region, knee

Stage II

Radiography: mixed osteopenia and/or subchondral sclerosis and/or subchondral cysts without subchondral lucencies (Figure 1).

MRI: geographic pattern

Clinical findings: painful restriction of hip joint movement

\section{Stage III}

Radiography: crescent (sickle) sign and possibly collapse of the subchondral bone (Figure.2)

MRI: crescent (sickle) sign and possibly collapse of the subchondral bone

Clinical findings: painful restriction of hip joint movement and/or pain irradiating to the knee joint, limp

\section{Stage IV}

Radiography: final stage with significant secondary degenerative changes (Figure.3).

MRI: similar to the radiography

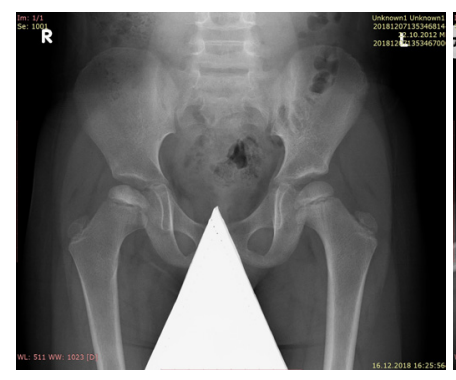

(a)

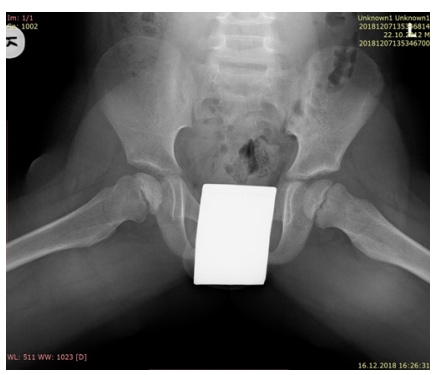

(b)
Fig. 1. Radiographs of the pelvis in the anteroposterior (a) and Lauenstein (b) views: LCPD, right side, stage II.

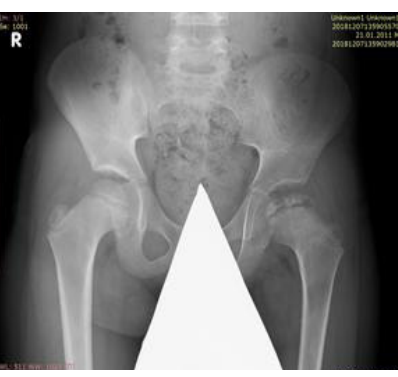

(a)

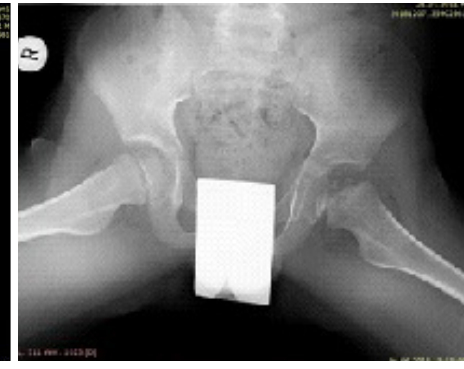

(b)
Fig. 2. Radiographs of the pelvis in the anteroposterior (a) and Lauenstein (b) views: LCPD, right side, stage III.

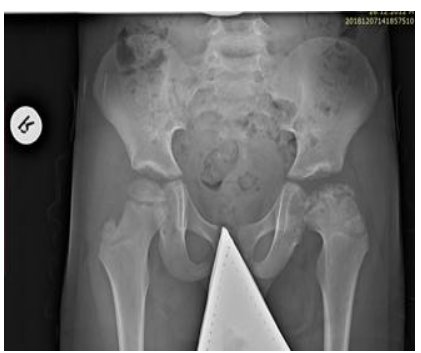

(a)

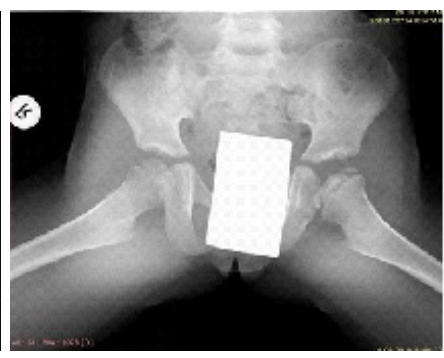

(b)
Fig. 3. Radiographs of the pelvis in the anteroposterior (a) and Lauenstein (b) views: LCPD, right side, stage IV.

Radiography remains the most useful imaging technique for LCPD. However, this method is non-informative at an early stage; this fact often results in late diagnosis. ${ }^{(11)}$

Radiologically there are 4 stages of aseptic necrosis ${ }^{(12)}$ (G. Axhausen, 1923):

1.The stage of primary subchondral necrosis of spongeous bone and marrow of the femoral head.

2.The stage of impression fracture. Necrotic trabeculae are compressed into bone powder. The strong elements of the connective tissue dissect the crushed head into sequesters; there are cysts with gigantic cells or adipose accumulations.

3. The stage ofepiphysis fragmentation. This degenerative and dystrophic process can go on for years and transforms into the next stage of reparative osteochondrogenesis.

\section{Stage of reparation}

At the first stage, the reliability of diagnosis using minimal clinical findings and radiographic signs is only $8 \%-$ $10 \%{ }^{(13)}$ Radiography shows an insignificant widening of the articular space and a decrease of the epiphysis height compared to the healthy side. Ultrasound and MRI are recommended to 
visualize the synovial membrane, the articular effusion, and cartilage lesions. MRI is a method of choice for diagnosing LCPD at its early stages. Exudative synovitis and soft tissue edema are the most frequent signs. The presence of reactive trabecular edema of the marrow of the femoral head and neck is a characteristic of the early stage of aseptic osteonecrosis ${ }^{(9,14)}$ (Figure 4).

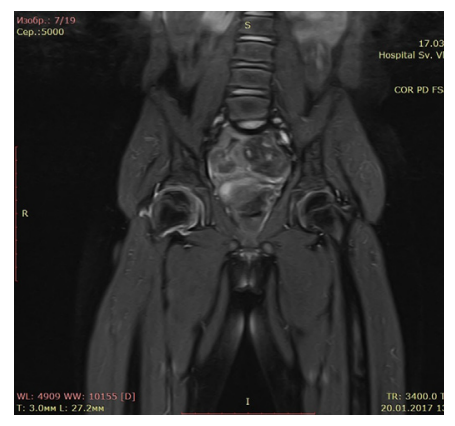

(a)

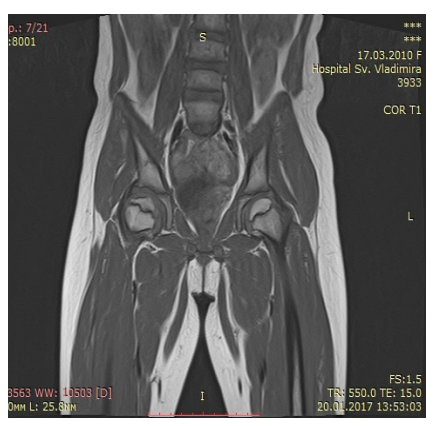

(b)
Fig. 4. MRI, PD Fat Sat (a), T1 (b), frontal view: LCPD, right side, stage I.

The pain syndrome in the debut of LCPD is an indication for ultrasound (US) examination of the hip joints. ${ }^{(15)}$ A longitudinal scanning is traditionally performed along the frontal surface of the joint. The neck-to-capsule distance (from $3 \mathrm{~mm}$ in newborns to $8 \mathrm{~mm}$ in adolescents), the capsule margin (normally, concave, more or less parallel to the neck), the width of the synovial membrane (about $2 \mathrm{~mm}$ ), and the effusion should be assessed. ${ }^{(16)}$ Evaluation of the bone margin fragments of the femoral head and metaepiphyseal area is obligatory (normally, margins are well defined but could be irregular due to metaepiphyseal ossification). An examination of the contralateral joint must also be performed. In the debut of LCPD, it is typical to find US signs of coxitis, such as synovial membrane thickening up to $2-4 \mathrm{~mm}$, a trace or small volume of effusion, deformed capsule outlines, and an increase in the neck-to-capsule distance (reliably $-2 \mathrm{~mm}$ or more compared to the unaltered contralateral side). The decrease in the head height with irregular epiphyseal margins cannot always be visualized with certainty with US, so it is an absolute indication for using other imaging modalities. ${ }^{(17)}$

At the second stage, the head is devoid of a structural pattern; its density increases and it becomes homogeneous. A thin lucent line appears around the denser part of the epiphysis while the epiphyseal height continues to decrease. At this moment the structural changes in the head can be visualized using radiography. On MRI, there is a zone of necrosis in the epiphysis clearly limited by a double line along the peripheral area (the outer layer of ossification and the inner layer of hypervascularized tissue). The secondary changes are the exudative hypertrophic synovitis, thinning of the articular cartilage and ligament impairment (Figure 5).

At the third stage, radiological signs are best expressed. It becomes possible to visualize the resorption of the necrotized zone, articular space enlargement in all the segments, and a decrease in the epiphyseal height. The epiphysis is more flattened, displaced upwards and laterally from the tear and crescent figures; it loses its structural pattern, breaks into sequester-like structureless zones of various configuration, and the neck becomes shorter and thicker ${ }^{(3)}$ (Figure 6) .

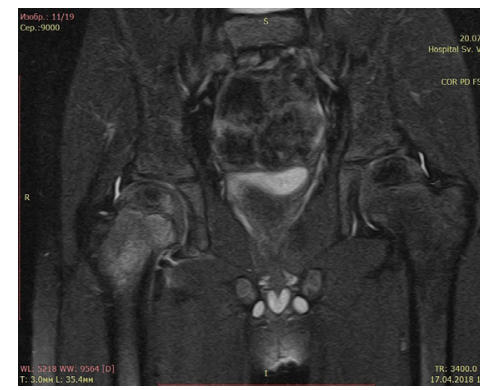

(a)

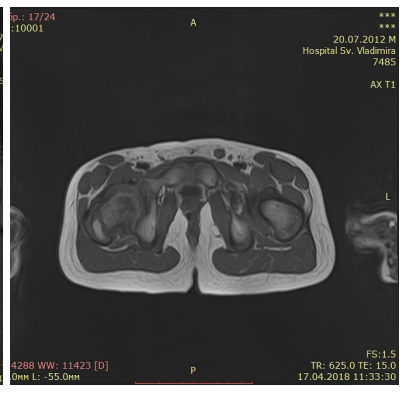

(b)
Fig. 5. MRI, PD Fat Sat, frontal view (a), T1, axial view (b): LCPD, right side, stage II.

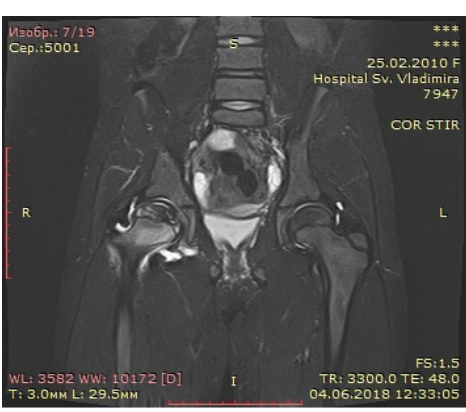

(a)

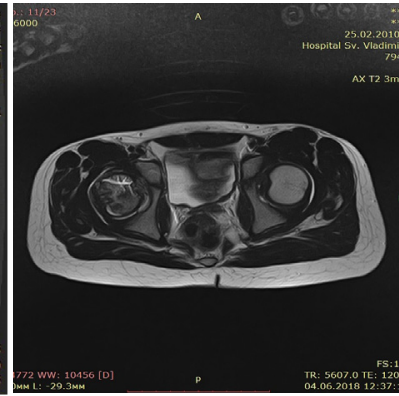

(b)
Fig. 6. MRI, STIR, frontal view (a), T2, axial view (b) - LCPD, right side, stage III.

At the fourth stage, there is a distinct epiphyseal lamina, the trabecular structure is restored and the sequester-like bone fragments disappear. The structure in the zone of former necrosis and in adjacent parts becomes more homogeneous, the epiphyseal height increases, although the structural pattern of the head remains rough, and the trabecula are disorderly directed. The width of the articular space decreases due to normalization of endosteal and enchondral osteogenesis.

At the stage of the outcome of aseptic necrosis, MRI shows the depressed epiphyseal fracture and empty necrotic place without a free fragment. There are some secondary degenerative changes in the joint (i.e. focal cartilage thinning and ligament degeneration). ${ }^{(14)}$

Thus, the most frequent and constant radiological signs are enlargement of the articular space (epiphyseal displacement upwards and laterally), epiphysis flattening and sclerosis, soft tissue thickening, subepiphyseal osteoporosis, narrowing of the femoral neck and loosening of epiphyseal lamina.

Introduction of multislice computer tomography (MSCT) into clinical practice permits detection of the signs inaccessible to radiography because of polyprojectional visualization of the articular elements and absence of summation for planning surgical treatment. It is necessary to emphasize the role of MSCT at the final stages of aseptic necrosis: the transformation of the fragmentation stage into the stages of reparation and outcome. It is very important 
due to the necessity to resolve on the weight bearing for the limb of interest. MSCT is a more informative method than radiography for necrosis staging at early times; it is possible to estimate a correlation in the joint and to exclude any pathological changes in the femoral neck and acetabular roof. However, the presence of an X-ray negative pattern in the first stage and in the beginning of the second one leads to use of the imaging modality that could show the femoral head at the stage of bone marrow edema-MRI. In addition, MRI can provide assessment of the chondral and soft elements, the synovium, and the volume of ischemic zone in the proximal part of the femur.

US of the hip joints is widely used, absolutely harmless unlike radiography and $\mathrm{CT}$ and can be repeatedly performed to assess these X-ray negative structures, such as muscles, tendons and capsules. US permits visualization of the transitory synovitis and detection of an irregularity of articular surfaces before any bone changes. It also reveals, or arouses suspicion of, LCPD at the early stage when radiologic signs are not to be seen. Doppler US successfully demonstrates the microcirculation in the hip joint area before and after surgery as a control for osteogeneous reparative processes as the presence and dynamics of interfragmental blood supply reflect the efficiency of treatment. ${ }^{(7)}$

In recent studies there are references to digital tomosynthesis of bones and joints for the assessment of structural changes. Additionally, the subchondral changes at the initial stages of the diseases can also be visualized. ${ }^{(18)}$ The information value is higher than radiography and linear tomography but lower than MSCT. ${ }^{(19)}$

In conclusion, early diagnosis and treatment of LCPD are the key points of the prevention of childhood disability. The need to develop early diagnosis of hip joint diseases in children is well understood: the implementation of diagnosis and treatment standards, the precise examination algorithm, and the modern imaging modalities. Despite the great number of publications concerning early diagnosis of LCPD, the number of children with late stages of this disease is still high.

\section{Conflict of Interest} interests.

The authors declare that they have no competing

\section{References}

1. Stalmakhovich VN, Dudenkov VV, Dyukov AP, Dmitrienko AP. [Surgical treatment of the acquired deformation of the thorax at children]. Siberian Medical Journal (Irkutsk). 2010;97(6):232-233. [Article in Russian].

2. Kamosko MM, Poznovich MS. [Radiological diagnosis of hip joint abnormalities in children]. Pediatric Traumatology, Orthopaedics and Reconstructive Surgery. 2015;3(2):32-41. [Article in Russian].

3. Mirskaya NB, Kolomenskaya AN, Sinyakina AD. [Medico-social significance of disorders and diseases of the musculoskeletal system of children and adolescents (literature review)]. Gig Sanit. 2015;94(1):97-104. [Article in Russian]. 4. Krutikova NYu, Vinogradova AG, 2015. [Legg-CalvePerthes disease]. Current pediatrics. 2015;14(5):548-52. [Article in Russian].

5. Catterall A, Chir M. Thoughts on the etiology of Perthes' disease. The Iowa Orthopaedic Journal. 1984;4:34-36.

6. Dementsov AB. [Perthes disease: etiology, clinical presentation, pathogenesis, treatment methods]. Meditsinskie novosti. 2013;7(18). [Article in Russian].

7. Tikhonenko TI, Vybornov DYu, Gurevich AI, Lozovaya YuI. [Ultrasound examination of the hip joints in assessing the effectiveness of treatment of children with Legg-Calve-Perthes disease and coxarthritis]. Pediatric Traumatology, Orthopaedics and Reconstructive Surgery. 2014;2(3):68-75. [Article in Russian]. 8. Leroux J, Abu Amara S, Lechevallier J. Legg-Calvé-Perthes disease. Orthop Traumatol Surg Res. 2018;104(1S):S107-S112. doi: 10.1016/j.otsr.2017.04.012.

9. Laine JC, Martin BD, Novotny SA, Kelly DM. Role of Advanced Imaging in the Diagnosis and Management of Active Legg-Calvé-Perthes Disease. J Am Acad Orthop Surg. 2018 Aug 1;26(15):526-536. doi: 10.5435/JAAOS-D-16-00856.

10. Ficat RP, Arlet J. Necrosis of the femoral head. In: Hungerford DS, eds. Ischemia and necrosis of bone. Baltimore, Md: Williams \& Wilkins; 1980:171-182.

11. Mazloumi SM, Ebrahimzadeh MH, Kachooei AR. Evolution in diagnosis and treatment of Legg-Calve-Perthes disease. Arch Bone Jt Surg. 2014;2(2):86-92.

12. Axhausen G. Der anatomische Krankheitsverlauf bei der Kohlerschen Krankheit der Metatarrsalkopfchen und derPerthes'schen Krankheit des Huftkopfes. Arch Klin Chir. 1923; 124:511-542.

13. Ibrahim T, Little DG. The Pathogenesis and Treatment of Legg-Calvé-Perthes Disease. JBJS Rev. 2016;4(7). pii: 01874474201607000-00003. doi: 10.2106/JBJS.RVW.15.00063.

14. Bryukhanov A, Vasiliev AYu. Magnetic resonance imaging in osteology. M., Meditsina; 2006. [In Russian].

15. Menshchikova TI, Maltseva LV. [Features of ultrasound diagnostics of the initial manifestations of Legg-Calve-Perthes disease in children]. Mezhdunarodnyi Zhurnal Prikladnyh i Fundamentalnyh Issledovanii. 2015;(2-1):54-58. [Article in Russian].

16. Golovkin SI, Utkin VA, Kravets YM, Shabaldin NA. [X-ray and ultrasonographical criteria of prediction of unfavorable course of the synovitus of the hip joint in children during the initial examination]. Mother and Baby in Kuzbass. 2016;(2):20-28. [Article in Russian].

17. Kozhevnikov VV, Osipiv AA, Grigiricheva LG, Voronchihin EV, Timoshenskaya NV, Lobanov MN, et al. [Ultrasound dopplerography of the hip joint and correction of the disorders revealed in children with dystrophic changes in femoral head]. The Ilizarov Journal of Clinical and Experimental Orthopaedics (Genij Ortopedii). 2015;(1):4752. [Article in Russian].

18. Vasilyev AYu, Karpov SS. [Efficacy analysis of tomosynthesis in the diagnosis of the femoral head osteochondropathy (Legg-Calvé-Perthes disease)]. Almanac of Clinical Medicine.2017;45(1):14-22. [Article in Russian].

19. Bogolepova NN, Rostovtsev MV. [Use of tomosynthesis in children's medical institution]. Pediatricheskii Vestnik Yuzhnogo Urala. 2013;2:49-56. [Article in Russian]. 